\title{
Step Structures Produced by Hydrogen Etching of Initially Step-Free (0001) 4H-SiC Mesas
}

\author{
J. Anthony Powell ${ }^{1}$, Philip G. Neudeck ${ }^{2}$, \\ Andrew J. Trunek ${ }^{3}$ and Phillip B. Abel ${ }^{4}$ \\ ${ }^{1}$ Sest Inc., NASA Glenn, 21000 Brookpark Rd., MS 77-1, Cleveland, OH 44135 USA \\ ${ }^{2}$ NASA Glenn Research Ctr., 21000 Brookpark Rd., MS 77-1, Cleveland, OH 44135 USA \\ ${ }^{3}$ OAI, NASA Glenn, 21000 Brookpark Rd., MS 77-1, Cleveland, OH 44135 USA \\ ${ }^{4}$ NASA Glenn Research Ctr., 21000 Brookpark Rd., MS 23-2, Cleveland, OH 44135 USA \\ 1J.A.Powell@grc.nasa.gov, ${ }^{2}$ Neudeck@nasa.gov, ${ }^{3}$ Andrew.J.Trunek@grc.nasa.gov, \\ ${ }^{4}$ Phillip.B.Abel@nasa.gov
}

\section{Keywords: 4H-SiC, AFM, Hydrogen Etching, Step-Free Surface, Stepflow Etching}

\begin{abstract}
This paper presents new observations resulting from in-situ high temperature hydrogen etching of $4 \mathrm{H}-\mathrm{SiC}$ mesas that were step-free prior to initiation of etching. In particular, it was found that well-ordered pyramidal-shaped step train structures could be produced on mesa top surfaces via stepflow etching proceeding inward from the sides of mesas. In many cases, the height of steps etched inward from $\{11 \overline{2} 0\}$ mesa sides is $0.5 \mathrm{~nm}$ ( $2 \mathrm{Si}-\mathrm{C}$ bilayers), while the height of steps etched inward from $\{1 \overline{1} 00\}$ sides of the same mesa is $1.0 \mathrm{~nm}$ (4 Si-C bilayers, the repeat distance of the $4 \mathrm{H}-\mathrm{SiC}$ polytype). We propose that stepflow etching starting from the mesa sidewall and involving step-to-step repulsive forces produces the observed step train structures.
\end{abstract}

\section{Introduction}

We have previously reported patterned arrays of epitaxially grown (0001) on-axis $4 \mathrm{H}-$ and $6 \mathrm{H}-\mathrm{SiC}$ mesas as large as $400 \mu \mathrm{m} \times 400 \mu \mathrm{m}$ with top surfaces completely free of atomic scale steps [1]. These step-free mesas offer a unique platform for studying fundamental growth and etching behavior beyond what is observable on conventional $\mathrm{SiC}$ substrates whose surfaces suffer from pre-existing steps (due to a non-zero surface tilt angle), screw dislocations, and polishing damage. For example, step-free (0001) 4H-SiC mesa surfaces have recently been employed to grow 3C-SiC and $\mathrm{GaN}$ heterofilms exhibiting unique behavior and unprecedented low dislocation densities compared to films nucleated on conventional (stepped) $\mathrm{SiC}$ wafer surfaces [2-4]. This paper presents new observations resulting from high temperature hydrogen etching of step-free $4 \mathrm{H}-\mathrm{SiC}$ mesas.

\section{Experimental}

Prior to etching, step-free mesas were formed using previously described experimental procedures and a growth system with an uncoated graphite susceptor $[1,3,4]$. Except for changes in temperature and etch time, in-situ etching was carried out under the same reactor conditions of 200 mbar pressure and $4400 \mathrm{~cm}^{3} / \mathrm{min} \mathrm{H}_{2}$ flow. Etching was terminated by ramping off the RF induction heating power in 2 minutes or less and cooling to room temperature in $\mathrm{H}_{2}$ flow. Samples were then characterized by differential interference contrast (DIC) optical microscopy and tapping-mode atomic force microscopy (AFM). 


\section{Results}

As an illustrative example of the most significant observed behaviors, Figs. 1 and 2 show results from a selected $100 \mu \mathrm{m} \times 100 \mu \mathrm{m}$ mesa that was first grown to have a step-free (0001) surface, and then subjected to a series of various high temperature etching processes. The complete sequence of etching processes carried out on this sample is summarized in Table 1. It is important to note than only Etch \#1 was initiated from a step-free surface on this particular sample; all subsequent etches initiated from existing steps left behind by the preceding etch.

The morphology of the mesa following Etch \#1 (1460 ${ }^{\circ} \mathrm{C}$ for $10 \mathrm{~min}$.) was essentially the same as the morphology observed following Etch $\# 5\left(1660^{\circ} \mathrm{C}\right.$ for $2 \mathrm{~min}$.) shown in Figs. 1 and 2. Figure 1 shows the differential interference contrast (DIC) optical micrograph of a resulting mesa "rooftop" (named after its optical appearance), while the Fig. 2 AFM scan of the central portion of the mesa surface reveals the pyramidal step pattern. The step pattern and smooth terraces between steps shown in Fig. 2 indicate stepflow etching proceeded inward from the sides of the mesa. Smooth step edges run mostly parallel to the mesa sidewalls aligned with $\{11 \overline{2} 0\}$ and $\{1 \overline{1} 00\}$ crystallographic planes. The height of steps etched inward from $\{11 \overline{2} 0\}$ mesa sides (left and right sides of Figs. 1 and 2 ) is $0.5 \mathrm{~nm}$ ( $2 \mathrm{Si}-\mathrm{C}$ bilayers). The height of steps etched inward from $\{1 \overline{1} 00\}$ mesa sides (top and bottom sides of Figs. 1 and 2) is $1.0 \mathrm{~nm}$ (four Si-C bilayers, the repeat distance of the 4H-SiC polytype). Similar etching behavior for similar etching conditions was observed on many mesas on several other $4 \mathrm{H}-\mathrm{SiC}$ samples etched using similar conditions. However, we note that macrostep formation (step bunching) and associated large terrace formation was also observed on some mesas of all samples.

For lower temperature etches (such as Etch \#6 at $1240{ }^{\circ} \mathrm{C}$ for $10 \mathrm{~min}$.), existing step edges that were previously smooth became somewhat jagged in

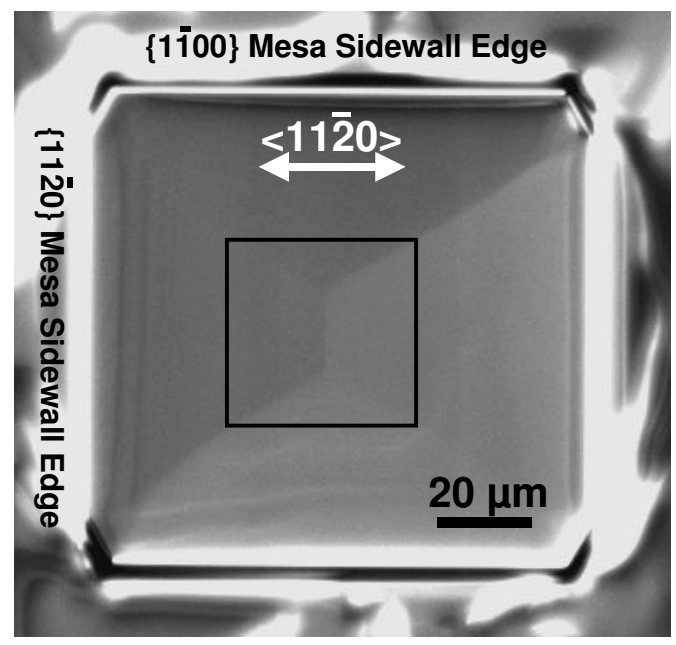

Fig. 1: Optical micrograph of mesa "rooftop" produced by in-situ etching of initially step-free $4 \mathrm{H}-\mathrm{SiC}$ epitaxial mesa. The box shows the region where the Figure 2 AFM scan was recorded.

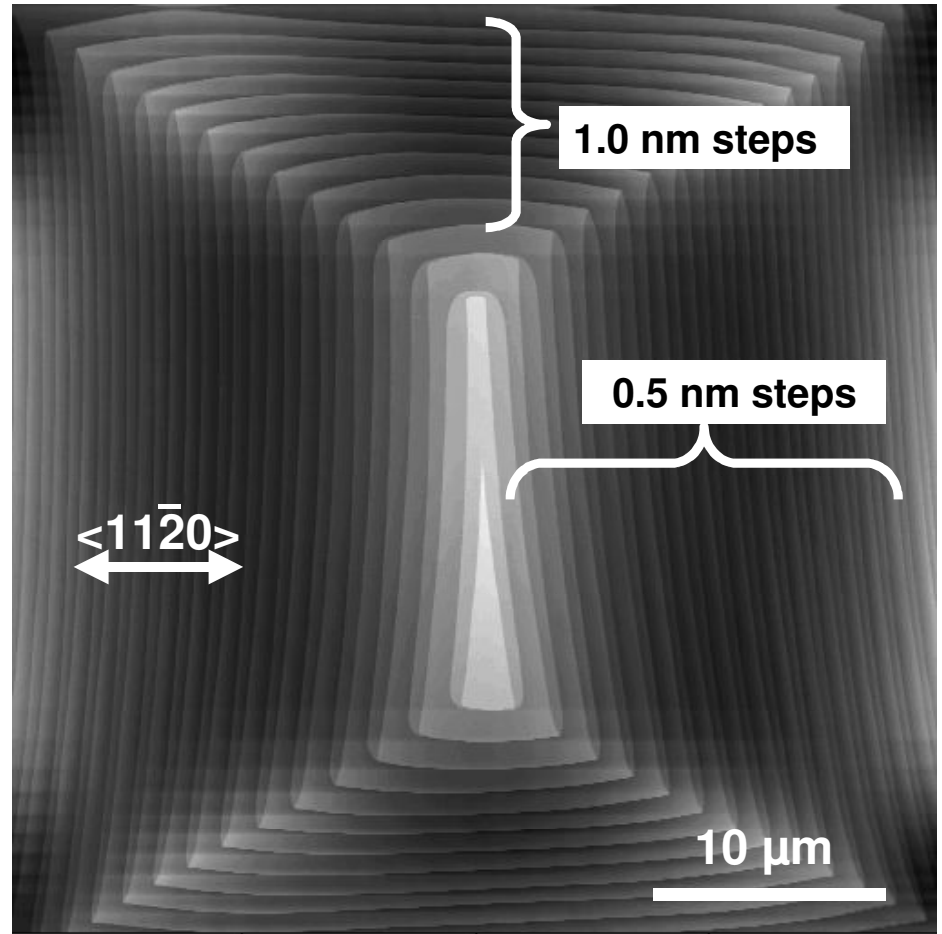

Fig. 2: AFM scan of peak of Fig. 1 mesa rooftop region following Etch \#5 $\left(\mathrm{H}_{2}\right.$ at $1660{ }^{\circ} \mathrm{C}$ for $2 \mathrm{~min}$.) showing pyramidal step pattern (rooftop) created by stepflow etching. A nearly identical step pattern was obtained after Etch \#1, which started from a step-free epitaxial mesa surface. 
appearance, as shown in the closeup AFM image of Fig. 3. The jagged step-edge shape on such samples tended to exhibit consistent "up arrow" and "down arrow" bias features, examples of which are denoted in Fig. 3. The "up" and "down" stepfront configurations alternate every $0.5 \mathrm{~nm}$ downstep on the left and right sides. Another general observed trend of lower temperature etch conditions was that existing $1.0 \mathrm{~nm}$ steps from the $\{1 \overline{1} 00\}$ (top and bottom) mesa sides tended to dissociate into multiple steps of smaller stepheight, such as the $0.5 \mathrm{~nm}$ height steps highlighted by white arrows in the lower left of Fig. 3.

\section{Discussion}

The crystallographic etching behavior of the mesas is qualitatively consistent with previous (0001) $4 \mathrm{H}-$ and $6 \mathrm{H}-\mathrm{SiC}$ high temperature gaseous etching studies [5-10]. Even though our work starts from a step-free surface with no pre-existing tilt (i.e., perfectly (0001) on-axis), steps coming inward from $\{1 \overline{1} 00\}$ mesa sides (top and bottom of Figs. 1 and 2) produce a small local surface tilt toward $<1 \overline{1} 00>$. Therefore, it is not surprising that heights of steps on these sides of the mesa rooftop correspond to the height of full stacking repeat sequence $(1.0 \mathrm{~nm}$ for $4 \mathrm{H}-\mathrm{SiC})$ as previously observed for gaseous etching of large-wafer surfaces offcut toward $<1 \overline{1} 00>[8,10]$. Similarly, the heights of steps etching inward from $\{11 \overline{2} 0\}$ mesa sides (left and right sides of Figs. 1 and 2 ) are half the height of the $4 \mathrm{H}$ polytype stacking repeat sequence $(0.5 \mathrm{~nm})$, also consistent with previous observations on wafers offcut toward $<11 \overline{2} 0>[8,10]$. A number of works have previously proposed that differences in the etching or growth velocity of particular $\mathrm{Si}-\mathrm{C}$ bilayers in the polytype stacking sequence lead to coalescence of single bilayer height steps into half and full polytype stacking height steps [8-11]. It has also been suggested that bilayers in the quasihexagonal local stacking environment etch more rapidly than bilayers in the quasi-cubic local stacking environment $[7,8]$.

A key uniqueness in this work is the fact that no steps existed on the mesa top surface region prior to the start of the first post-growth etch. To form the observed ordered step patterns during the first etch, successive bilayers must preferentially etch inward from the top of the mesa sidewall. Previous growth observations of highly periodic steps on (0001) SiC surfaces have proposed step-to-step repulsive interaction as a key driving mechanism behind wellordered step trains [12]. We suggest that the same strong driving mechanism must also be present during etching in order for such highly periodic steps (Fig. 2) to evolve from initially step-free mesa tops. When etching conventional $\mathrm{SiC}$ wafer surfaces, the lateral step density is greatly impacted by surface offcut angle and direction. In contrast, etching initiated from the step-free (0001) surface does not suffer tilt-angle bias, thus enabling the observation of natural interstep spacings for various experimental etching conditions. Further experimental study over broader experimental conditions (including sample parameters such as polytype) is needed to elucidate key factors governing step train behavior. Nevertheless, it is worth noting that there was negligible difference in interstep

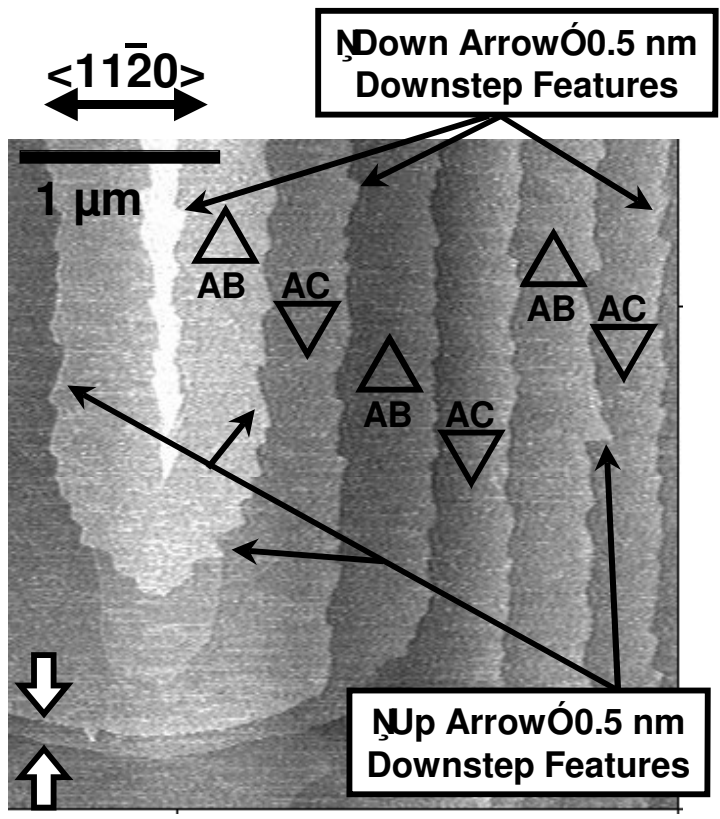

Fig. 3: AFM close-up of step pyramid top following lower-temperature $\left(1240 \quad{ }^{\circ} \mathrm{C}\right)$ Etch \#6. White arrows show two $0.5 \mathrm{~nm}$ height steps formed by dissociation of previously $1.0 \mathrm{~nm}$ step. The jagged $0.5 \mathrm{~nm}$ height steps begin to exhibit cubic-like facet shape (triangles) with up arrow or down arrow bias according to the cubiclike stacking $(\mathrm{AB}$ or $\mathrm{AC})$ of the topmost two $4 \mathrm{H}-\mathrm{SiC}$ bilayers of each terrace. 
spacing between Etches \#1 and \#5, despite the fact that significantly different etch temperatures were employed.

For the low temperature etching of existing "rooftop" steps, we suggest that jagged step-edge structures arise because the much slower etch rate (and lower surface adatom diffusion length) permits exposed bilayers to begin to etch with facet character corresponding to the $3 \mathrm{C}$ stacking of the topmost two $4 \mathrm{H}-\mathrm{SiC}$ bilayers on each step terrace $[4,11]$. The alternating "up arrow" and "down arrow" edge features along the stepfronts denoted in Fig. 3 (especially along the $\{11 \overline{2} 0\}$ left and right sides) are consistent with the fact that $4 \mathrm{H}$ polytype stacking alternates between the oppositely rotated $3 \mathrm{C}$ variants (i.e., $\mathrm{AB}$ and $\mathrm{AC}$ stacked terraces labelled in Fig. 3) every two bilayers $(0.5 \mathrm{~nm})$. The black triangles in Fig. 3 illustrate the corresponding cubic facets, consistent with the observed evolution of the jagged-edge step pattern. We also suggest that such cubic micro-faceting contributes to the splitting of $1.0 \mathrm{~nm}$ steps from the $\{1 \overline{1} 00\}$ (top and bottom) mesa sides into smaller steps (such as those denoted by white arrows in Fig. 3), due to the fact that one of the $3 \mathrm{C}$ variants (i.e., two of the $4 \mathrm{H}$ bilayers in each step previously $1 \mathrm{~nm}$ high) would present a relatively stable (111) $3 \mathrm{C}-\mathrm{SiC}$ microfacet along (i.e., paralleling) a $\{1 \overline{1} 00\}$ stepfront, while the oppositely cubic-stacked bilayers (i.e., the other two bilayers in each previously 4-bilayer height step) does not. However, further study is needed to better elucidate more complete understanding of observed step microstructure at low temperature.

\section{Conclusion}

Initial observations resulting from high temperature gaseous hydrogen etching of $4 \mathrm{H}-\mathrm{SiC}$ mesas that were step-free prior to initiation of etching have been presented. It was found that step-pyramid-like structures could be produced on the top (0001) mesa surfaces. Observed step patterns were a function of the etch temperature and mesa sidewall crystallographic orientation.

\section{Acknowledgements}

The authors are grateful for assistance from M. Mrdenovich, E. Benavage, B. Osborn, K. Walker, P. Lampard, C. Blaha, M. Artale, J. Gonzalez, G. Beheim, D. Spry, G. Hunter, and L. Matus. Work carried out under the Technology Transfer Partnership and Ultra Efficient Engine Technology projects at NASA Glenn Research Center.

\section{References}

[1] J.A. Powell, et al.: Appl. Phys. Lett. Vol. 77 (2000), p. 1449.

[2] N.D. Bassim, et al.: IEEE/TMS Electronic Materials Conference (2004), p. 32.

[3] P.G. Neudeck, et al.: Mater. Sci. Forum Vol. 389-393 (2002), p. 311.

[4] P.G. Neudeck and J.A. Powell: in Recent Major Advances in SiC, W.J. Choyke, H. Matsunami, and G. Pensl, Editors (Springer-Verlag: Heidelberg, Germany, 2003) p. 179.

[5] A.A. Burk, Jr. and L.B. Rowland: J. Crystal Growth Vol. 167 (1996), p. 586.

[6] C. Hallin, et al.: J. Crystal Growth Vol. 181 (1997), p. 241.

[7] J.A. Powell, D.J. Larkin, and A.J. Trunek: Mater. Sci. Forum Vol. 264-268 (1998), p. 421.

[8] S. Nakamura, et al.: Appl. Phys. Lett. Vol. 76 (2000), p. 3412.

[9] Z.Y. Xie, et al.: J. Crystal Growth Vol. 271 (2000), p. 115.

[10] W. Wulfhekel, et al.: Surface Science Vol. 550 (2004), p. 8.

[11] J.A. Powell and D.J. Larkin: Phys. Stat. Solidi (b) Vol. 202 (1997), p. 529.

[12] N. Ohtani, et al.: Phys. Rev. B Vol. 59 (1999), p. 4592. 